Research Article

\title{
Assessment of Study Skills among B.Sc. Nursing Students of Selected Nursing Colleges of Mangalore, Karnataka, India
}

\author{
Theresa Leonilda Mendonca
}

Professor, Laxmi memorial College of Nursing, AJ Towers, Balmatta, Mangalore, Karnataka, India. DOI: https://doi.org/10.24321/2348.2141.201903

\section{I $\quad \mathbf{N} \quad \mathbf{F} \quad \mathbf{O}$}

E-mail Id:

leedapga@yahoo.com

Orcid Id:

https://orcid.org/0000-0003-1480-212X

How to cite this article:

Mendonca TL. Assessment of Study Skills among B.Sc. Nursing Students of Selected Nursing Colleges of Mangalore, Karnataka, India. Trends Nurs Adm Edu 2019; 8(1): 13-17.

Date of Submission: 2019-01-15

Date of Acceptance: 2019-06-25

\section{$\begin{array}{llllllll}\mathbf{A} & \mathbf{B} & \mathbf{S} & \mathbf{T} & \mathbf{R} & \mathbf{A} & \mathbf{C} & \mathbf{T}\end{array}$}

In most of the nursing institutions considerable attention is given to the definition of the content of the curriculum organization of teaching and conduct of assessment and examination. Unfortunately, little attention has been given to the impact of the activities on the way and the patterns students used to study. The way that students approach their study skills has an important impact on the outcome of any educational endeavour. Considering the impact of approaches and study skills, it seems important for curriculum planer and assesses the study skills of nursing students.

Aim: To determine the level of study skills among B.Sc. (N) students.

Methods: A descriptive survey approach was used with random sampling technique to select 120 nursing students. The data was collected using Baseline Proforma and Study Skill Assessment Checklist. The scores would be analysed using frequency and percentage, mean, standard deviation, median, mean percentage and ANOVA.

Results: Study skills among all the year students were more or less, similar. Among first year mean score was highest for preparing for test [mean=32] and taking notes [mean=30]. Even second year also had highest mean score for preparing for test and taking notes [mean=33]. Third year and fourth year had highest mean score for preparing for test and studying. Findings of the study showed that majority of the nursing students had the skill of taking notes.

Keywords: Assess, Nursing Students, Students, Study Skills

\section{Introduction}

Study skills are an array of skills which tackle the process of organizing and taking new information, retaining information or dealing with assessments they include mnemonics, which aid the retention of lists of information, effective reading, concentration techniques and efficient note taking. ${ }^{1}$ It seems that student's lack of interest and enthusiasm in reading while studying lessons on the one hand and their inability to recall the lessons studied on the other hand result from their poor study skills and reading strategies. ${ }^{2}$ One of the most important necessities in higher education system is the development and reinforcement of the study skills of students. In recent decade, extensive research has 
been conducted on students study skills and strategies, but only in developed countries. ${ }^{3}$ Nursing students are probably liable for more stress than other students during the first year of study due to clinical and classroom tasks. ${ }^{4}$ Hence early in the nursing course the principle of learning should be used such as a way of thinking, feeling, dealing with critically appraising data, obtaining empathy and professional relationships management are in demand especially in first year students.

Nursing students are young budding nursing professionals who will be trained to serve the patients and there by the society. One of the most important necessities in nursing education system is the development and reinforcement of the study skills of the students. ${ }^{5}$ In recent decades, extensive research has been conducted on students' study skills and strategies but only in developed countries.

The nursing profession has a tight schedule for the younger nurses. If we glance at the master academic plan of nursing curriculum it seems to be much hectic and comprising a lot of subjects than any other health discipline. The academic theory and practical block are tightly scheduled and at times it is exhausting, a specially when there is a partial block system. It is not an easy task to concentrate the theory classes after a heavy five hours of clinical, such situation it is highly impossible to grasp everything what is taught in the classroom. Hence, it is important to recall and further refresh again in the hostel or at home in regular basis by adopting a healthy study skill. It is essential to analyse the study skills and take corrective action. The mentors and teachers need to conduct regular assessment of their student's study skill and counsel on identifying the weakness.

\section{Objectives of the Study}

- To determine the level of study skills among the BSc Nursing students.

- $\quad$ To compare the study skills among $1^{\text {st }}, 2^{\text {nd }}, 3^{\text {rd }}$ and $4^{\text {th }}$ year B.Sc. nursing students.

\section{Materials and Methods}

A descriptive research design was used to achieve the aim of the study. The study was conducted in two selected nursing colleges of Mangalore The study involved a group of 120 nursing students studying in $1^{\text {st }}, 2^{\text {nd }}, 3^{\text {rd }}$ and $4^{\text {th }}$ year B Sc nursing classes, from each class 15 students were selected thus from each college 60 students participated in the study. Students who are willing to study were included and those who have already participated in similar kind of study were excluded from the study. A self-administered questionnaire form was utilized to collect the data. It consists of two parts. The first part is concerned with students' characteristics and academic data The second part of the tool consists of the Study Skills questionnaire It is a 30 item questionnaire that measures six study skills; text book reading, note taking, memory, test preparation, studying and time management. The scale has 3-point Likert scale Rarely, sometimes, often with scoring $0,5,10$ respectively. A total score of each sub scale is calculated by simple summation of the scores of its item, A total score of 30 - 51 indicates solid skill and score 0-30: need improvement.

\section{Ethical Considerations}

After obtaining ethical clearance from institutional ethics committee and permission from college authority, the purpose and nature of the study was clarified to the students. The researcher confirmed that the information they gave would not affect their grade in courses and that data would be utilized only for the purpose of scientific study. Confidentiality was guaranteed by assigning each subject a code number.

Data was collected from $20^{\text {th }}$ July 2018 to 25 July2018. It was planned to analyze the data using descriptive and inferential statistics.

\section{Statistical Analysis}

For descriptive statistics, frequency and percent were used to describe the students' characteristics, as well as the study variables. Means and standard deviations were used to describe skills of students' ANOVA test was used to compare the study skills among different batch of students. Statistical significance was considered at $p$-value $<0.05$.

\section{Result}

Equal number of students was selected from each class of study. Most of them (95.83\%) were females. most (97.5\%) of them were residing in the hostel.

Table I.Range of score, mean, standard deviation of study skill assessment scale

$(\mathrm{N}=120)$

\begin{tabular}{|c|c|c|c|c|}
\hline & Range of score & Mean & Standard deviation & Interpretation \\
\hline Reading textbook & $0-50$ & 25 & 9.5 & Need improvement \\
\hline Taking notes & $5-50$ & 30 & 10.13 & Need improvement \\
\hline Studying & $5-50$ & 30 & 9.40 & Need improvement \\
\hline Memorizing & $10-45$ & 30 & 9.453 & Need improvement \\
\hline Preparing for test & $5-50$ & 33 & 8.59 & Solid skill \\
\hline Managing time & $0-45$ & 25 & 8.75 & improvement \\
\hline
\end{tabular}


Table 2.Gender wise comparison of study skills assessment

$(\mathrm{N}=120)$

\begin{tabular}{|c|c|c|}
\hline \multirow{2}{*}{ Study skill } & \multicolumn{2}{|c|}{ Mean score } \\
\cline { 2 - 3 } & Male & Female \\
\hline Reading textbook & 25 & 25 \\
\hline Taking notes & 32 & 30 \\
\hline Studying & 27 & 30 \\
\hline Memorizing & 36 & 29 \\
\hline Preparing for notes & 31 & 30 \\
\hline Managing time & 25 & 25 \\
\hline
\end{tabular}

Table 3.Area-wise comparison of mean and standard deviation of study skill areas among $\mathbf{I}^{\text {st }}$, $2^{\text {nd }}, 3^{\text {rd }}, 4^{\text {th }}$ year B.Sc. nursing students

$(\mathrm{N}=120)$

\begin{tabular}{|c|c|c|c|c|}
\hline Year & & Mean & SD & Evaluation \\
\hline \multirow{6}{*}{ First year } & Reading Textbook & 23 & 8.215 & Need Improvemen \\
\hline & Taking Notes & 30 & 9.95 & Need Improvemen \\
\hline & Studying & 29 & 7.18 & Need Improvemen \\
\hline & Memorizing & 31 & 7.30 & Solid Skill \\
\hline & Preparing for Test & 32 & 7.5 & Solid Skill \\
\hline & Managing Time & 26 & 8.2 & Need Improvemen \\
\hline \multirow{6}{*}{ Second year } & Reading Textbook & 25 & 8.06 & Need Improvemen \\
\hline & Taking Notes & 33 & 10.56 & Solid Skill \\
\hline & Studying & 29 & 11.10 & Need Improvemen \\
\hline & Memorizing & 30 & 9.17 & Need Improvemen \\
\hline & Preparing For Test & 33 & 8 & Solid Skill \\
\hline & Managing Time & 25 & 9.2 & Need Improvemen \\
\hline \multirow{6}{*}{ Third year } & Reading Textbook & 23 & 10.08 & Need Improvemen \\
\hline & Taking Notes & 28 & 9.48 & Need Improvemen \\
\hline & Studying & 30 & 9.87 & Need Improvemen \\
\hline & Memorizing & 28 & 10.9 & Need Improvemen \\
\hline & Preparing For Test & 32 & 9.3 & Solid Skill \\
\hline & Managing Time & 22 & 8.8 & Need Improvemen \\
\hline \multirow{6}{*}{ Fourth year } & Reading Textbook & 27 & 11.43 & Need Improvemen \\
\hline & Taking Notes & 29 & 10.52 & Need Improvemen \\
\hline & Studying & 30 & 8.99 & Need Improvemen \\
\hline & Memorizing & 29 & 9.44 & Need Improvemen \\
\hline & Preparing for Test & 31 & 9.3 & Solid Skill \\
\hline & Managing Time & 24 & 8.8 & Need Improvemen \\
\hline
\end{tabular}

Table 4.One way ANOVA to compare the difference in study skill between, first year, second year, third year, and fourth year B. Sc nursing students

$(\mathrm{N}=120)$

\begin{tabular}{|c|c|c|c|c|c|}
\hline & Sum of squares & df & Mean square & f & Sig \\
\cline { 1 - 3 } Between groups & 7205.359 & 3 & 2401.786 & \multirow{2}{*}{0.459} & \multirow{2}{*}{0.712} \\
\cline { 1 - 3 } Within groups & 607518.633 & 116 & 5237.230 & & \\
\hline Total & 614723.992 & 119 & & & \\
\hline
\end{tabular}


Area wise analysis shows that except 'preparing for test ' all the other areas needs improvement (Table 1). Among males mean score was highest for memorizing (mean=36), taking notes (mean $=32$ ) and preparing for test (mean=31), whereas among females mean score was similar for the three skills. Both among males and females mean score was similar (mean=25) for the skills managing time and reading text books. Study. Skills among all the four-year students were more or less similar (Table 2).

Among first year mean score was highest for "preparing for test" (mean=32) and "taking notes" (mean=30) and least for "reading textbook" (mean=23). Even third years and who had highest mean score for "preparing for test" and "taking notes" (mean=33). Third year and fourth year had highest mean score for "preparing for test" and "studying. The lowest study skills in first year is "reading text book," the lowest study skills in second, third and fourth year is 'managing time' (Table 3).

There was no significant difference between the study skills of $1^{\text {st }}, 2^{\text {nd }}, 3^{\text {rd }}$ and $4^{\text {th }}$ year nursing students $(p=0.712)$ (table 4$)$.

\section{Discussion}

This study was conducted to examine the students' use of study skills. The current study findings indicates that majority of the students need improvement in the study skills consistent with previous Indian study on assessing study habits among nursing students reported that the subjects were having moderate study habits. ${ }^{6} \mathrm{~A}$ variety of studies conducted abroad had reported lacking of students' study habits. ${ }^{7,8,9,10,11}$ Furthermore, present study findings are contrast to the findings of a study 'The relationship between the Study Habits and the Academic Achievement of Students' in that study, the majority of students had moderate or moderately good study habits. ${ }^{12}$ In the study conducted on Study Skills and Habits and Some Related Factors in Kurdistan university of Medical Sciences, the study habits of the students were at a moderate level. ${ }^{13}$

In the present study 'reading text book' time management ', 'studying', 'memorizing' are the areas needs improvement. In a study carried out in Zanjan University of Medical Sciences, the major problems of the students were found to be 'Time management', 'Concentration', 'Studying speed', and 'Class note-taking'. 'Time management' was considered to be the students' most important problem. In order to prevent and solve such a problem, it is recommended that the students should be taught how to reduce the pauses between their studying sessions and remove the distracters. ${ }^{14}$

\section{Conclusion}

Improving and promoting the study skills of graduate students require the designing and implementing of education programs for study strategies Also, Study habits seem to be an essential. It is suggested that college administration in collaboration with teachers should implement such intervention plans and workshops for developing effective study habits. Moreover, In view of the relationship between study habits and academic achievement and significance of nursing education, the students should be trained to promote their study habits and strategies. Time management' was considered to be the students' most important problem.

\section{Conflict of Interest: None}

\section{References}

1. Bremer R. The Manual: A Guide to the Ultimate Study Method. $2^{\text {nd }}$ ed. Fons Sapientiae Publishing.

2. Fatemeh S, Hamid RD, Abolghasem A et al. A study on the quality of study skills of newly-admitted students of Fasa University of Medical Sciences. J Adv Med Educ Prof 2014; 2(1): 45-50.

3. Alireza D, Hamid RK. Assessing study skills among a sample of university students: an Iranian survey. J Educ Eval Health Prof 2014; 11: 8 .

4. Amany SA, Eman MA. Enhancing study skills among freshman nursing students an intervention study. Journal of Nursing and Health Science 2018; 7(3): 22-29.

5. Fischer M, Boshoff EL, Ehlers VJ. Student nurses need for developing basic skills. Curationis 2001; 24(1): 66-73.

6. Narayanan A, Anu PJ, Anusha PN. Study Habits among Nursing Students of a Selected Educational Institute in Mangaluru, India. American International Journal of Research in Humanities, Arts and Social Sciences 2015; 13(3): 204-206. Available at: http://iasir.net/ AIJRHASSpapers/AIJRHASS15-868.pdf. Accessed on Nov., 2017.

7. Hussein $\mathrm{MH}$, Ahmadieh $\mathrm{MH}$, Shavazi MA et al. Study Skills in Bachelor Students In The School Of Public Health, Yazd, 2006. Strides Dev Med Educ 2008; 5(2): 88-93.

8. Fereidouni M, Cheraghian B. Study habits and their relationship with academic performance among students of abadan school of nursing. Strides Dev Med Educ 2009; 6(1): 21-28.

9. Badeleh MT, Charkazi AR, Asayesh H et al. Study skills in Golestan University of medical sciences: a neglected need. Journal of health 2011; 8(4): 643-649.

10. Mirzaei M, Rastani IH, Sepahvand E et al. Study Skills and Its Related Factors in Jahrom University of Medical Sciences in 2014. IOSR Journal of Dental and Medical Sciences (IOSR-JDMS) 2015; 14(10): 77-81.

11. Sharma G. Study Habits of Class Viii Students: A Comparative Analysis. International Journal of Research in Applied, Natural and Social Sciences (Impact: Ijranss) 2017; 5(6): 79-88. 
12. Mashayekhi F, Rafati S, Mashayekhi M et al. The relationship between the Study Habits and the Academic Achievement of Students in Islamic Azad University of Jiroft Branch. International Journal of Current Research and Academic Review 2014; 2(6): 182-187.

13. Zarezadeh Y, Rasolabadi M. Students' Study Skills and Habits and Some Related Factors in Kurdistan university of Medical Sciences. Journal of Medical Education Development of Zanjan 2015; 8(17): 29-38.

14. Nourian A, Mousavinasab N, Fahri A et al. Medical student's study skills and habits in Zanjan University of Medical Sciences. IJME 2006; 6(1): 101-107. 